\title{
Extraction of Quantitative Data from Lithium Polymer Battery Micrographs
}

\author{
Marin Lagacé*, Pierre Hovington*, Chantal Baril**, Elisabeth Dupuis*, Pierre Noel* \\ *Hydro-Québec Research Center, 1800 boul. Lionel-Boulet, Varennes, Québec, Canada, J3X 1S1 \\ **LTEE Research Center, 600 avenue de la Montagne, Shawinigan, Québec, Canada, G9N 7N5
}

The lithium polymer battery (LPB) is an energy storage technology that gives one of the highest energy/weight ratio making it one of the best candidates for use in both electric and hybrid cars. The main problems reside in the morphological evolution of the cells with use and the high requirement in the components quality. The total thickness of a unit cell being less than $100 \mu \mathrm{m}$, the main physical characterisation tool used is the SEM. Micrographs are a great help in understanding the underlying phenomena influencing cell life but simple micrographs can only give a qualitative evaluation of cell morphology. To get quantitative results, we must turn to image analysis [1].

One of the parameters influencing cell life is the morphological evolution of the electrolyte. On an uncycled cell, the electrolyte is of uniform thickness (see Figure 1). Upon cycling, the morphology of the electrolyte changes making it more and more irregular [2] (see Figure 2). An image analysis procedure was designed to isolate the electrolyte component and measure its width in numerous places using an evaluation grid. The procedure being automated, numerous micrographs can be analysed giving good statistical results. The electrolyte width histogram can then be drawn giving not only the average width but also an evaluation of the overall roughness of the electrolyte upon cycling (see Figure 3). Quantitative and objective comparison of electrolyte morphology can then be done between different cells and cycling protocols (see Figure 4).

Another morphological parameter that arise in some LPB using very thin lithium is the creation of pinholes in the lithium during cycling (see figure 5). Using simple micrographs, we can only get a qualitative evaluation of the pinhole density. Using image analysis, we can measure and plot the distribution of the distance between pinholes. Comparison between cells tested using different cycling parameters shows the same overall pattern (see Figure 6). This seems to indicates that the pinhole distribution is mainly influenced by the lithium sheet microstructure. This result could not have been obtained without the use of image analysis.

In conclusion, image analysis can extract extremely useful quantitative data from micrographs. It can be used to characterise morphological parameters giving insight into working mechanism or giving valuable quality control information. The speed and computing power of modern computers enables the user to automate the analysis procedures allowing for the easy and fast analysis of numerous images giving good statistical results.

\section{References}

[1] John C. Russ, Computer-Assisted Microscopy: The Measurement and Analysis of Images, Plenum Press, New York, 1990.

[2] Yamaki J-I et al, Journal of Power Sources, 74 (1998), pp. 219-227

[3] The image analysis software used was designed and written by the author. 

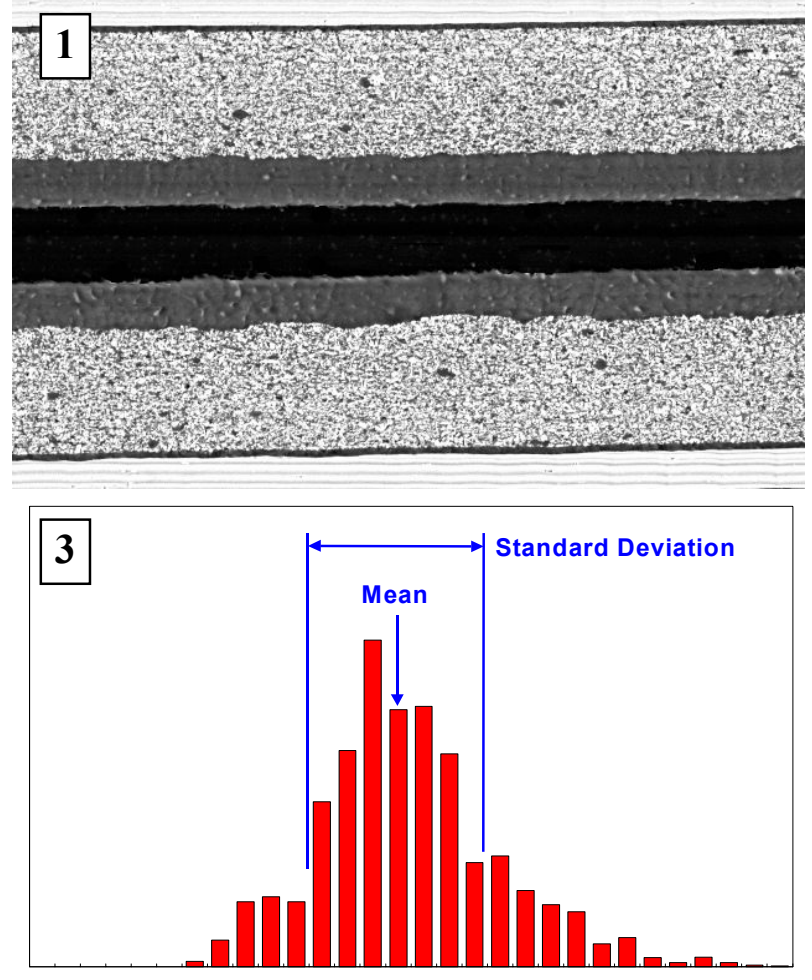

Width $(\mu \mathrm{m})$

FIG. 1. Uncycled cell.

FIG. 2. Cycled cell.

FIG. 3. Histogram of electrolyte width.

FIG. 4. Comparison of three different cells.
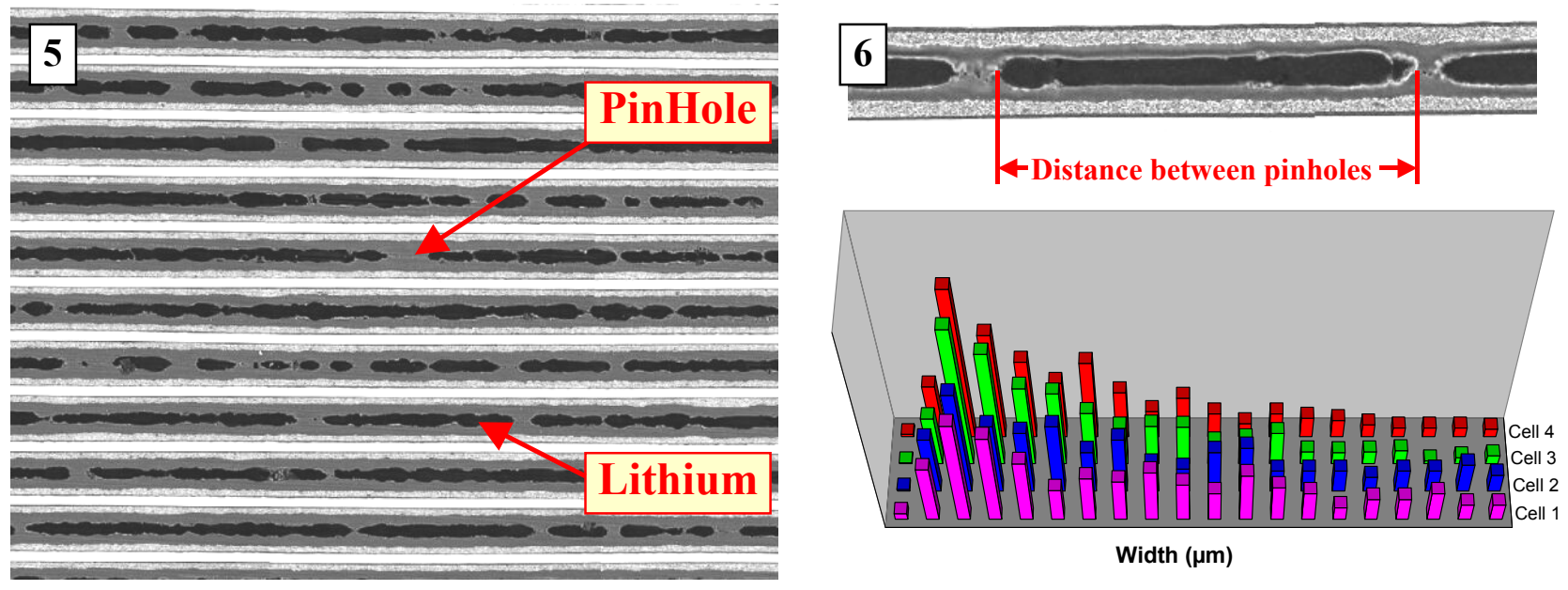

FIG. 5. Presence of pinholes in the lithium sheets.

FIG. 6. Distribution of distances between pinholes.
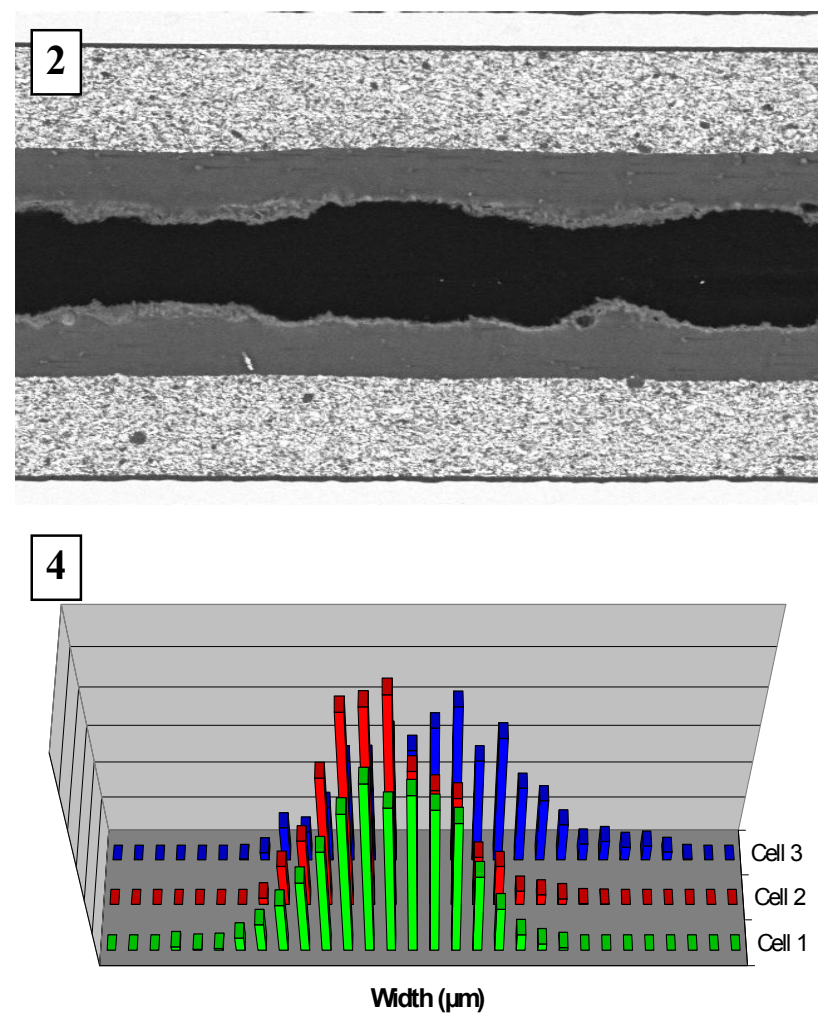

Width $(\mu \mathrm{m})$ 